\title{
Modification of Severe Violent and Aggressive Behavior among Psychiatric Inpatients through the Use of a Short-Term Token Economy
}

\author{
Park, Jae Soon ${ }^{1}$ Lee, Kyunghee ${ }^{2}$ \\ ${ }^{1}$ College of Nursing, Keimyung University, Seong Dong Mental Hospital, Daegu \\ ${ }^{2}$ College of Nursing, Keimyung University, Daegu, Korea
}

\begin{abstract}
Purpose: Meager research has been carried out to determine the effectiveness of the token economy among patients behaving violently in mental hospitals. The purpose of this study was to examine the effectiveness of the Short-Term Token Economy (STTE) on violent behavior among chronic psychiatric in-patients. Methods: A nonequivalent control group design method was utilized. Participants in an experimental group $(n=22)$ and control group $(n=22)$ took part in this study from January to April, 2008. Observation on aggressive behavior among male in-patients in one hospital as a baseline was made during the week before the behavior modification program and measurement of aggressive behavior was done using the Overt Aggression Scale (OAS), which includes verbal attacks, property damage and physical attacks. Results: The aggressive behavior scores of the experimental group decreased, those of the control group, scores showed an increase after the eight-week behavior modification program utilizing STTE. Conclusion: The results of the study indicate that STTE is effective in reducing the incidence of aggressive behavior among male in-patients in psychiatric hospitals. The outcome of this study should be helpful in reducing the use of coercive measures or psychoactive medication in controlling the violent behavior among in-patients in hospitals.
\end{abstract}

Key words: Token economy; Behavior therapy; Aggression; Psychiatric

\section{INTRODUCTION}

Mental illness frequently makes the individual more aggressive due to the psychological instability. In addition, psychiatric inpatients perceived environmental conditions and poor communication to be the significant precursor of aggressive behavior who were dissatisfied with a restrictive and under-resourced provision that leads to interpersonal tensions (Han, Tsai, Chen, \& Chen, 2012; Pearson, Wilmot, \& Padi, 1986).

There were several studies which showed the relevant associated factors of the violent behaviors in psychiatric unit. These factors were more likely to be male, less than 45 years old, and those from diagnosis of schizophrenia (Chukwujekwu \& Stanley, 2011; Pearson et al., 1986) use of temporary nursing staff(James, Fineberg, Shah, \& Priest, 1990); previous aggressive and disturbed behavior (Noble \& Rodger, 1989); criminal record and previous drug abuse (Walker \& Seifert, 1994).

The occurrence of the aggressive behavior in the unit could harm himself, other staff or therapeutic environment. Aggressive behavior against self and others is a frequent symptom of schizophrenia in the first two years and was significant predictor during the previous two years after first admission (Steinert, Wiebe, \& Gebhardt, 1999). The psychiatric nurses are working with the patients directly for 24 hours a day. Hence, they get to experience the aggressive behaviors directly from the patients. Kim (2010) reported that the subjective evaluation of inpatient's violence by psychiatric nurses includes: verbal aggressive behavior

\footnotetext{
* This study is a condensation of the first author's master thesis in 2008.

Address reprint requests to : Lee, Kyunghee

College of Nursing, Keimyung University, 1095 Dalgubeoldaero, Dalseo-gu, Daegu 704-701, Korea

Tel: +82-53-580-3927 Fax:053-580-3916 E-mail:khl645@kmu.ac.kr

Received: June 14, 2012 Revised: July 23, 2012 Accepted: December 8, 2012
} 
(96.2\%), aggressive behavior on others (84\%), aggressive behavior on certain objects (79.7\%) and self-injury (77.7\%). Aggressive behaviors of psychiatric patients may be caused by environmental or biological factors, so the psychiatric interventions that incorporate medication and behavior therapies are the most effective (Corrigan, Yudofsky, \& Silver, 1997). Because effective and efficient nursing intervention for patients with treatment should be applied, modification of severe violent and aggressive behavior is urgently needed which are not traditional nursing intervention. According to the decision tree to guide decisions about pharmacological and behavioral treatments of aggression depending on where in the course of the disorder patients exhibit difficulty by Corrigan, Yudofsky, and Silver, the token economy could be the most comprehensive behavioral tool for producing a well-structured milieu.

Coercive measures are often used to manage the imminent violence including seclusion, restraint and enhanced observation as token economy. However, the seclusion and use of restraints are often misapplied and patients become more aggressive during the process of compulsory coercion (Poulsen \& Engberg, 2001). One of the arbitrating methods to control the aggressive behavior among psychiatric inpatients is the behavior modification therapy based on the token reinforcement which applies the principle of affirmative reinforcement (Abramowitz et al., 2012; Ayllon \& Azrin, 1965; Kazdin, 1973).

However, limited studies exist in the literature that examined the effect after providing the STTE on aggressive behavior among inpatients in the psychiatric unit. This study aimed to fill in the gap in the literature. This study specifically aims to measure the effect of the behavior modification using STTE on aggressive behavior among inpatients in the psychiatric hospital.

The research hypothesis of this study is as follows:

It is hypothesized that aggressive behavior scores of the experimental group who receives the STTE will be more increased than the aggressive behavior scores of the control group.

\section{METHODS}

\section{Participants}

By $G^{*}$ Power 3.13, the total sample size of 32 subjects was calculated through effect size of .25 , alpha of .05 , a power of .80 and repeated measures by 5 times. Permission for accessing and using the data was obtained from the director of one hospital (there was no formalized Insti- tutional Review Board [IRB] procedure). This study included 44 subjects, all male, between 30 to 60 years of age and who agreed on and signed for this study. They have experienced the coercive measures including seclusion and restraint during one month before the experimental treatment because of past violent history against themselves, to other patients and staff. The experimental and control groups are segregated from each other by the wards.

All 44 male subjects in the intervention and comparison groups were assessed to meet the criteria for a diagnosis of psychiatric disorder based on Diagnostic Statistical Manual of Mental Disorder, 4th Edition (DSM-IV) and independent clinical assessment. The researchers were able to locate and implement all the STTE in the intervention group $(n=22)$. During the period of treatment, each of the notes in the hospital admission data and aggressive behavior were the $7^{\text {th }}$ sessions on their average.

\section{Measurements}

Most data of the participants' aggression in this study were obtained using the instruments utilized in Yudofsky et al.'s study (1986) wherein their psychometric properties were fully described (pp. 35-39). Stepwise or leveled token systems have been employed to maintain the desirable behaviors and the beneficial effects of treatment, hence, constitute another technique to enhance generalization. Since these measures are widely used and to prevent repetition, only brief descriptions of instruments used in the study were provided as indicated below.

\section{1) Overt Aggression Scale (OAS)}

The Overt Aggression Scale (Yudofsky, Silver, Jackson, Endicott, and Williams, 1986) was chosen to assess participant's aggressive behavior across the domains of verbal attack, property damage and physical attack. The Overt Aggression Scale (OAS), designed to assess observable aggressive or violent behavior rather than tendencies, is divided into two parts. The first section consists of four categories: a) verbal aggression, b) property damage, c) physical aggression against self and d) physical aggression against other people. Within each category, aggressive behavior is rated according to its severity. The second part of the scale rated the staff intervention at the time of the aggressive incident. The total score of aggression was calculated in the same way as that the scores of aggressive items (ranging from minimum one point to maximum sixteen points) plus the scores according to staff intervention (from minimum zero 
point to maximum ten points) and total maximum scores were 26 points. The Overt Aggression Scale is easy to complete and reliable for rating aggressive events. The scale makes it possible to document and to quantify verbal and physical overt aggressive behaviors. The intraclass correlation coefficients of reliability (ICC) showed good reliability (greater than .75) for most items (20).

\section{2) Smile sticker as tokens}

The token program requires individuals to begin at an initial level and depending on their improvement and sustained performance will allow them to progress to higher levels. Initial level requires the performance of few behaviors and offer few reinforcers: The participants were given one smile sticker as a token with the verbal reinforcement if the participant would not commit any aggressive behavior for one day ( 24 hours). The participants wrote down 3 items that they like in order of priority. Then, the reinforcers were selected according to the choice of the majority.

They were outlined as below.

In case of collecting three stickers: A cup of coffee

In case of collecting seven stickers: A bowl of zhajiangmian, noodles with black bean sauce

In case of collecting ten stickers: Half of fried chicken

In case of collecting fifteen stickers: A walk

In case of collecting twenty stickers: An outdoor activities

In case of collecting thirty stickers: A sleeping-in

In case of the diabetic patient: A cup of Job's tears tea instead of a cup of coffee, a bowl of udong (noodles in soup) instead of a bowl of zhajiangmian were provided.

\section{Procedures}

Permission for accessing and using the data was obtained from the directors of the hospitals. All participants who were asked to participate in the study agreed and signed the informed consent. Consents from participants were obtained from family members over the telephone.

Data were collected from January 14 to April 6, 2008. Ten research assistants who were trained for the study observed the aggressive behaviors of the participants in a psychiatric ward and checked their scores of aggression in the violent.

\section{1) The staff meeting}

During the regular ward meeting, the researcher explained that this study aimed to modify the aggressive behavior among patients in the psychiatric ward using STTE and to decrease the use of seclusion and restraint among patients who were not able to control their aggressive impulse. All staff agreed with the goals of this study. The researchers decided to proceed with the behavior modification therapy, and discussed the standards of the process. A discussion on the standards of selecting the objects and agreement with the team approach under the rules was preferred to be followed based on a consensus.

\section{2) A conditioned positive reinforcer}

The participants were asked about what's best for them as a conditioned positive reinforcer and discussed exhaustively together whether the reinforcers can be allowed or not in the ward. During the staff meeting, it was finally decided that the reinforcers will be in accordance with the number of stickers. The one-time coffee was purchased by three stickers and provided at 10:00 A.M in the nursing station, and the whole chicken and zhajiangmian were provided at 7:00 in the evening. The time for walking was allowed for 30 minutes in case of no possibility of escape and the accident.

\section{3) The training for research assistants}

For consistent maintenance of experimental treatment, the researcher educated ten psychiatric nurses in the ward regarding the procedure of behavior modification therapy and scoring method of aggressive behavior with Overt Aggression Scale (OAS) for 4 weeks. The researcher provided a demonstration on the process of measuring the scores on aggressive behavior using three given examples.

After the demonstration, the researcher had a meeting with the nurses individually three times a week for a month (total of 12 meetings). The researcher and the nurses compared the measured OAS scores with ten aggressive examples in patients' record. The interrater reliability of the OAS was tested through repetitive measuring practice and feedback exchange about the results. For the testing of interrater reliability of the OAS, comparisons of ratings of 10 same aggressive events were obtained. Finally, Pearson correlation coefficients of the ratings by all raters became 1.0 for the OAS.

\section{4) The procedure of behavior modification therapy}

\section{(1) Setting the baseline}

In order to measure the frequency and intensity of aggressive behavior 
among patients in the psychiatric ward, ten nurses on duty including the researcher had observed the characteristics of aggressive behavior for a week. The scores of aggressive behavior among the violent patients using OAS were recorded accordingly.

(2) The experimental group

During the time where the aggressive behaviors were not observed for 24 hours, the research assistants (nurses on duty) provided them with a sticker immediately at 8:00 A.M the following day. The token provided was attached to the notice board for confirming the number of stickers individually.

The experimental group was told that STTE for 12 weeks aimed to reduce the occurrence rate of the aggressive behavior and to decrease the use of coercive measures such as seclusion and restraints. The researchers made an emphasis on the collected stickers that can be exchanged to reinforcers whichever they wanted for once a day and reiterated that stickers used could not be used repeatedly and non-transferable.

The experimental group was provided with the sticker and verbal reinforcement like "Good job!" The researcher and nurses met together once a week, and checked out the changes of the scores on aggressive be- havior among the patients based on the records every second week from the time the research was initiated.

\section{Statistical analysis}

For statistical analyses, SPSS for Windows Program (version 12.0) was utilized. Group differences between the experimental group and the control group were analyzed utilizing repeated measures ANOVA.

\section{RESULTS}

\section{Sample characteristics and homogeneity test}

Among the 44 patients in the sample, 12 patients (27.3\%) were diagnosed as schizophrenia. Twelve patients $(27.3 \%)$ received a diagnosis of bipolar disorder; five (22.7 \%) had an alcohol dependence, and five (22.7 \%) had a diagnosis of personality disorder.

Group differences of general characteristics between the experimental group and the control group were found to be not significantly different (Table 1). Furthermore, group differences of dependent variables be-

Table 1. Homogeneity Test of Characteristics between Experimental and Control Groups

$(N=44)$

\begin{tabular}{|c|c|c|c|c|c|}
\hline \multirow{2}{*}{ Characteristics } & \multirow{2}{*}{ Categories } & \multirow{2}{*}{$\begin{array}{c}\text { Exp. }(n=22) \\
n(\%)\end{array}$} & \multirow{2}{*}{$\begin{array}{c}\text { Cont. }(n=22) \\
n(\%)\end{array}$} & \multirow{2}{*}{$\chi^{2}$} & \multirow{2}{*}{$p$} \\
\hline & & & & & \\
\hline Education & $\begin{array}{l}\text { Less than high school graduation } \\
\text { High school graduate } \\
\text { College graduate }\end{array}$ & $\begin{aligned} 14 & (63.6) \\
7 & (31.8) \\
1 & (4.5)\end{aligned}$ & $\begin{array}{c}13(59.1) \\
8(36.4) \\
1(4.5)\end{array}$ & 0.10 & .949 \\
\hline Career & $\begin{array}{l}\text { Unemployed } \\
\text { Day laborer }\end{array}$ & $\begin{array}{r}6(27.3) \\
10(45.5)\end{array}$ & $\begin{array}{r}7(31.8) \\
10(45.5)\end{array}$ & 0.94 & .815 \\
\hline Religion & $\begin{array}{l}\text { Christian } \\
\text { Roman Catholic } \\
\text { Buddhist } \\
\text { Others } \\
\text { Atheist }\end{array}$ & $\begin{array}{c}2(9.1) \\
4(18.2) \\
11(50.0) \\
0(0.0) \\
5(22.7)\end{array}$ & $\begin{array}{c}3(13.6) \\
1(4.5) \\
10(45.5) \\
1(4.5) \\
7(31.8)\end{array}$ & 3.38 & .496 \\
\hline Marital state & $\begin{array}{l}\text { Single } \\
\text { Married } \\
\text { Divorce } \\
\text { Separation and others }\end{array}$ & $\begin{array}{c}1(4.5) \\
16(72.7) \\
2(9.1) \\
3(13.6)\end{array}$ & $\begin{aligned} & (4.5) \\
15 & (68.2) \\
3 & (13.6) \\
3 & (13.6)\end{aligned}$ & 0.23 & .972 \\
\hline Finances & $\begin{array}{l}\text { Middle } \\
\text { Low }\end{array}$ & $\begin{array}{r}5(22.7) \\
17(77.3)\end{array}$ & $\begin{array}{r}3(13.6) \\
19(86.4)\end{array}$ & 0.61 & .349 \\
\hline Diagnosis & $\begin{array}{l}\text { Schizophrenia } \\
\text { Bipolar disorder }\end{array}$ & $\begin{array}{l}6(27.3) \\
6(27.3)\end{array}$ & $\begin{array}{l}6(27.3) \\
6(27.3)\end{array}$ & 0.00 & 1.000 \\
\hline Type of behavior & $\begin{array}{l}\text { Verbal aggression } \\
\text { Physical aggression against objects } \\
\text { Physical aggression against self } \\
\text { Physical aggression against others }\end{array}$ & $\begin{array}{r}3(13.6) \\
10(45.5) \\
9(40.9)\end{array}$ & $\begin{array}{r}3(13.6) \\
11(50.0) \\
8(36.4)\end{array}$ & 0.11 & .948 \\
\hline & Total & 154 & 154 & & \\
\hline
\end{tabular}

Exp. $=$ Experimental group; Cont. $=$ Control group. 
tween the experimental group and the control group were not significantly different (Table 2).

\section{Group differences at follow-up}

The incidence rate of aggressive behavior was 178 cases during preintervention baseline, but the incidence rate decreased to 141 cases after STTE. In the experimental group, there was a decrease of $20.8 \%$ in the aggressive behavior compared with the comparison group after STTE. In the form of aggressive behavior, the number of verbal attack decreased from 87 to $63(27.6 \%)$ cases. The incidence rate of property damage or physical attack against oneself or against others decreased from 91 to $78(14.3 \%)$ cases.

In the control group, there were few changes in the number of aggres- sive behavior, ranging from 178 to 168 cases after STTE. In the form of the aggressive behavior, the number of verbal attacks decreased from 93 to $85(8.6 \%)$ cases after STTE (Table 3).

The aggressive behavior score of the experimental group was 53.95 at the baseline but the scores showed a continuously decreasing tendency during follow-up. In case of the control group, the aggressive behavior score was 54.04 at the baseline, but the score was rather increased after four weeks (Figure 1).

To test the research hypothesis, differences between the intervention and comparison groups during follow-up were first evaluated using repeated measures ANOVA models in which group was the between-subjects factor and the pre-intervention baseline score on the dependent measure has significant difference in reference to time $(\mathrm{F}=194.46$, $p<.001 ; \mathrm{F}=101.53, p<.001)$. In addition, the transaction of time $\times$

Table 2. Homogeneity Test of Dependent Variables between Experimental and Control Groups

$(N=44)$

\begin{tabular}{|c|c|c|c|c|}
\hline \multirow{2}{*}{ Variables } & Exp. $(n=22)$ & Cont. $(n=22)$ & \multirow{2}{*}{$\mathrm{t}$} & \multirow[b]{2}{*}{$p$} \\
\hline & $\mathrm{M} \pm \mathrm{SD}$ & $\mathrm{M} \pm \mathrm{SD}$ & & \\
\hline Age & $43.27 \pm 6.23$ & $43.05 \pm 6.28$ & 0.12 & .905 \\
\hline Duration of illness & $9.45 \pm 2.89$ & $9.41 \pm 3.07$ & 0.05 & .960 \\
\hline The number of hospitalizations & $7.05 \pm 2.30$ & $7.00 \pm 2.51$ & 0.06 & .950 \\
\hline The number of attacks & $7.91 \pm 2.76$ & $7.45 \pm 2.50$ & 0.57 & .570 \\
\hline
\end{tabular}

Exp. $=$ Experimental group; Cont. $=$ Control group.

Table 3. Changes in Intervention and Comparison Group by Aggressive Behavior Items

$(N=44)$

\begin{tabular}{|c|c|c|c|c|c|}
\hline \multirow{3}{*}{ Type of behavior } & \multirow{3}{*}{ Categories } & \multicolumn{2}{|c|}{ Exp. $(n=22)$} & \multicolumn{2}{|c|}{ Cont. $(n=22)$} \\
\hline & & Pretest & Posttest & Pretest & Posttest \\
\hline & & $\mathrm{n}(\%)$ & $\mathrm{n}(\%)$ & $\mathrm{n}(\%)$ & $\mathrm{n}(\%)$ \\
\hline \multirow[t]{5}{*}{ Verbal attack } & Shouts angrily & $27(15.2)$ & $21(14.9)$ & $28(15.7)$ & $27(16.1)$ \\
\hline & Mild insults & $40(22.5)$ & $26(18.4)$ & 42 (23.6) & $31(18.5)$ \\
\hline & Curses viciously & $19(10.7)$ & $16(11.3)$ & $22(12.4)$ & $27(16.1)$ \\
\hline & Threats of violence & $1(0.6)$ & $0(0.0)$ & $1(0.6)$ & $0(0.0)$ \\
\hline & Subtotal & $87(49.0)$ & $63(44.6)$ & $93(52.3)$ & $85(50.7)$ \\
\hline \multirow[t]{5}{*}{ Property damage } & Scattering clothing & $8(4.5)$ & $3(2.1)$ & $11(6.2)$ & $10(6.0)$ \\
\hline & Throwing objects & $18(10.1)$ & $17(12.1)$ & $20(11.2)$ & $24(14.3)$ \\
\hline & Smashing windows & $8(4.5)$ & $8(5.7)$ & $3(1.7)$ & $2(1.2)$ \\
\hline & Setting fire & $1(0.6)$ & $0(0.0)$ & $2(1.1)$ & $1(0.6)$ \\
\hline & Subtotal & $35(19.7)$ & $28(19.9)$ & $36(20.2)$ & 37 (22.1) \\
\hline \multirow[t]{5}{*}{ Physical attack against self } & Picks \& scratches skin & $2(1.1)$ & $0(0.0)$ & $1(0.6)$ & $0(0.0)$ \\
\hline & Bangs head & $5(2.8)$ & $5(3.5)$ & $6(3.4)$ & $3(1.8)$ \\
\hline & Bruises, minor burns & $1(0.6)$ & $2(1.4)$ & $0(0.0)$ & $0(0.0)$ \\
\hline & Mutilates self, makes deep cuts & $0(0.0)$ & $0(0.0)$ & $0(0.0)$ & $0(0.0)$ \\
\hline & Subtotal & $8(4.5)$ & $7(4.9)$ & $7(4.0)$ & $3(1.8)$ \\
\hline \multirow[t]{6}{*}{ Physical attack against } & Threatening gesture & 20 (11.2) & $21(14.9)$ & $15(8.4)$ & $9(5.4)$ \\
\hline & Pushing, kicking \& hitting & $28(15.7)$ & 22 (15.6) & $27(15.2)$ & $34(20.2)$ \\
\hline & Attacking (mild-moderate) & $0(0.0)$ & $0(0.0)$ & $0(0.0)$ & $0(0.0)$ \\
\hline & Attacking (severe) & $0(0.0)$ & $0(0.0)$ & $0(0.0)$ & $0(0.0)$ \\
\hline & Subtotal & $48(26.9)$ & $43(30.5)$ & $42(23.6)$ & $43(25.6)$ \\
\hline & Total & $178(100.0)$ & $141(100.0)$ & $178(100.0)$ & $168(100.0)$ \\
\hline
\end{tabular}

Exp. $=$ Experimental group; Cont. $=$ Control group 


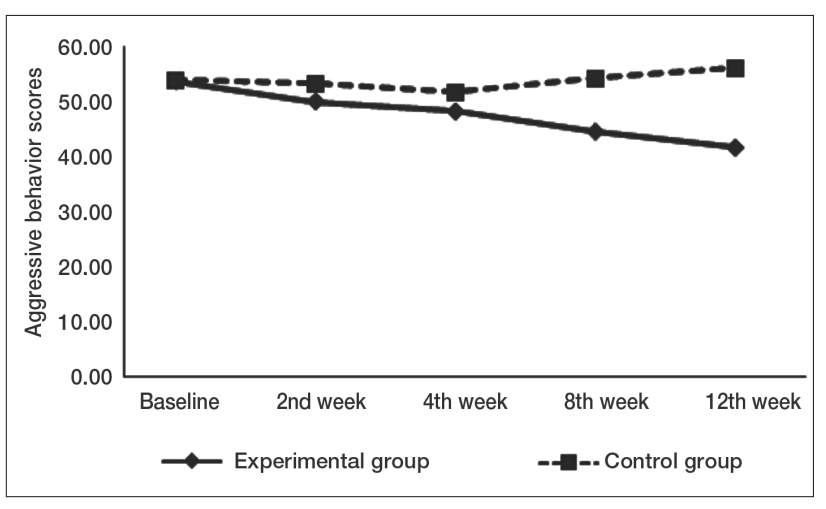

Figure 1. Changes in aggressive behavior scores.

group revealed significant difference $(\mathrm{F}=212.10, p<.001)$. Since the $p-$ value is less than the significance level $(p<.001)$, the research hypothesis was accepted (Table 4).

\section{Post Hoc Analysis of aggressive behavior score by simple main effect}

The researcher also explored the effect of the disaggregating the data for the intervention and the comparison group according to time by simple main effect (Table 4).

There were significant group differences by time (intervention group $\mathrm{F}=194.46, p<.001 ;$ comparison group $\mathrm{F}=98.22, p<.001)$.

Group differences by time in the aggressive behavior score were observed as below: pre-intervention baseline and 2 weeks score were found to be not significant $(\mathrm{F}=84.74, p=.084 ; \mathrm{F}=176.77, p=.051)$, but there were significant group differences after four weeks $(\mathrm{F}=396.85, p<.001)$, and there were significant differences after 8 weeks $(\mathrm{F}=369.33, p<.001)$, and after 12 weeks $(\mathrm{F}=392.55, p<.001)$.

Since there were significant group differences, a thorough review on the change of the disaggregating the data for the intervention and the comparison group by aggressive behavior items was made (Table 4).

\section{DISCUSSION}

During episode of aggressive behavior that occurred in the psychiatric ward, the use of coercive measures such as seclusion and restraint often violate the patient's human rights (Tedeschi \& Felston, 1994). Thus, this study aimed to reduce the aggressive behavior and to facilitate the adaptive behavior using token economy theory with the principle of positive reinforcement in a psychiatric hospital. It is generally known that the behavior patterns of people with chronic mental disorder could not be modified easily, but this study has shown significant group differences after two weeks.

The results of this study correspond with those of other studies using token as a form of Reinforcement (Hoffmeister, 1979; Lippman \& Motta, 1993).

The term of continuous validity in this experimental group took for about 12 weeks, but in the other study, the term was reported for about 5-12 weeks (Lippman \& Motta, 1993); some took for 6-12 months (Gripp \& Magaro, 1971). Because the psychiatric nurses who have experience with inpatient's aggression could express the aggressive behavior against them or against the patients (Bowers et al., 2005), they need to be educated about various form of aggressive behavior. It was reported that the aggressive behavior of the psychiatric disorder was different according to the characteristics of the hospital (Jang, 2004), the more patients the hospital accommodates, the higher the rate of executing restraints compared to general hospital, and the less number of nurses on duty, the more restraints were executed(Ha, 1993). As every hospital is different from the ward's environment and structure, the composition of patients,

Table 4. Simple Main Effect Analysis of Aggressive Behavior Scores

\begin{tabular}{|c|c|c|c|c|c|c|c|c|}
\hline \multirow{2}{*}{ Groups } & Base line & 2 weeks & 4 weeks & 8 weeks & 12 weeks & \multirow{2}{*}{ Sources } & \multirow{2}{*}{$\mathrm{F}$} & \multirow{2}{*}{$p$} \\
\hline & $\mathrm{M} \pm \mathrm{SD}$ & $\mathrm{M} \pm \mathrm{SD}$ & $\mathrm{M} \pm \mathrm{SD}$ & $\mathrm{M} \pm \mathrm{SD}$ & $\mathrm{M} \pm \mathrm{SD}$ & & & \\
\hline Exp. $(n=22)$ & $53.95 \pm 3.12$ & $50.27 \pm 1.95$ & $48.45 \pm 1.62$ & $44.81 \pm 2.17$ & $41.90 \pm 2.34$ & Time*Exp. & 194.46 & $<.001$ \\
\hline \multirow[t]{6}{*}{ Cont. $(n=22)$} & $54.04 \pm 1.55$ & $53.36 \pm 1.32$ & $51.86 \pm 1.45$ & $54.50 \pm 1.14$ & $56.22 \pm 0.92$ & Time*Cont. & 98.22 & $<.001$ \\
\hline & & & & & & G*Baseline & 84.74 & .084 \\
\hline & & & & & & $G^{\star} 2$ weeks & 176.77 & .051 \\
\hline & & & & & & $\mathrm{G}^{\star} 4$ weeks & 396.85 & $<.001$ \\
\hline & & & & & & $G^{\star} 8$ weeks & 369.33 & $<.001$ \\
\hline & & & & & & $G^{*} 12$ weeks & 392.55 & $<.001$ \\
\hline
\end{tabular}

Exp. = Experimental group; Cont. = Control group; $\mathrm{G}=$ Group. 
and the number of therapeutic teams, a comparative study according to the type of hospital such as the psychiatric ward in the general hospital or/and the chronic psychiatric hospital is highly recommended for future studies

A participant who had been very aggressive against his family turned out to be less aggressive after using STTE. It can be considered that the affirmative result was given by providing the chance for outdoor activities as a form of reinforcement in the behavior modification therapy, and the family could have the chance to confirm the subject's affirmatively changed behavior directly and become more concerned with the patient.

In order to sustain the behavior modification therapy utilized in this study, the researcher highly suggested a strong support system coming from the administrative policy and the institutional system in the hospital as well as the cooperation of the entire therapeutic staff.

Above all of these, the selection of reinforcers were shown differently according to the psychiatric diagnosis; inpatients with schizophrenia had the tendency to choose the victual such as coffee, zhajiangmian, fried chicken, etc., while inpatients with manic-depressive or the alcohol dependent had the tendency to choose the walking or the outdoor activities.

For future studies, the researcher highly recommends the utilization of more individualized and various forms of reinforcement. Additionally, there must be necessary follow up observation after the experimental treatment to evaluate the continuous effect of the STTE.

\section{CONCLUSION}

The general aim of this study which is to demonstrate the behavior modification therapy was found to be quite effective in decreasing the aggressive behavior among the inpatients with chronic psychiatric disorder in the hospital. A detailed understanding of the participant and the STTE may have modified the participants' aggressive behavior to become less aggressive after using it. As such, the behavior modification therapy is considered to be one of the most useful alternatives for the exchange of coercive measures in managing the violent and aggressive behavior in the clinical situation. It is expected that the potential benefits of STTE for inpatients of varying age, diagnosis, and type of psychiatric hospital will undergo investigation in controlled experimental studies to determine the effectiveness of token economy and advance the development of outcome measures, strategies, and methods to implement STTE in clinical settings.

\section{REFERENCES}

Abramowitz, J. S., Baucom, D. H., Wheaton, M. G., Boeding, S., Fabricant, L. E., Paprocki, C., et al. (2012 Aug 10. [Epub ahead of print]). Enhancing exposure and response prevention for OCD: A couple-based approach. Behavior Modification. http://dx.doi.org/10.1177/01454455 12444596

Ayllon, T., \& Azrin, N. H. (1965). The measurement and reinforcement of behavior of psychotics. Journal of the Experimental Analysis of Behavior, 8(6), 357-383. http://dx.doi.org/10.1901/jeab.1965.8-357

Bowers, L., Carr-Walker, P., Paton, J., Nijman, H., Callaghan, P., Allan, T., et al. (2005). Changes in attitudes to personality disorder on a DSPD unit. Criminal Behavior and Mental Health, 15(3), 171-183. http://dx.doi. org $/ 10.1002 / \mathrm{cbm} .5$

Chukwujekwu, D. C., \& Stanley, P. C. (2011). Prevalence and correlates of aggression among psychiatric in-patients at Jos University Teaching Hospital. Nigerian Journal of Clinical Practice, 14(2), 163-167. http:// dx.doi.org/10.4103/1119-3077.84007

Corrigan, P. W., Yudofsky, S. C., \& Silver, J. M. (1997). Pharmacological and behavioral treatments for aggressive psychiatric inpatients. In American Psychiatric Association (Ed.), Violent behavior \& mental illness: A compendium of articles from psychiatric services and hospital and community psychiatry (pp. 46-54). N. W. Washington, DC: American Psychiatric Pub

Gripp, R. F., \& Magaro, P. A. (1971). A token economy program evaluation with untreated control ward omparisons. Behaviour Research and Therapy, 9(2), 137-149. http://dx.doi.org/10.1016/0005-7967(71)90071-4

Ha,G. S. (1993). Clinical characteristics of violent behaviors among inpatients in large mental hospital. Journal of Korean Neuropsychiatric Association, 32(5), 660-668

Han, K. C., Tsai, Y. F., Chen, M. C., \& Chen, Y. Y. (2012). Violent schizophrenia patients: Caregiver burden and related factors. Hu Li Za Zhi, 59(2), 29-39.

Hoffmeister, F. (1979). Reinforcing properties of nicocodine in the rhesus monkey. Arzneimittelforschung, 29(5), 811-814.

Jang, S. J. (2004). Relationship between experience of patients' violent behaviors and burnout of psychiatric nurses. Unpublished master's thesis, Seoul National University, Seoul.

James, D. V., Fineberg, N. A., Shah, A. K., \& Priest, R. G. (1990). An increase in violence on an acute psychiatric ward. A study of associated factors. The British Journal of Psychiatry, 156, 846-852. http://dx.doi.org/ 10.1192/bjp.156.6.846

Kazdin, A. E. (1973). Issues in behavior modification with mentally retarded persons. American Journal of Mental Deficiency, 78(2), 134-140.

Kim, Y. O. (2010). Analysis of nursing intervention according to type of aggressive behavior in psychiatric inpatients. Unpublished master's thesis, Ewha Womans University, Seoul.

Lippman, M. R., \& Motta, R. W. (1993). Effects of positive and negative reinforcement on daily living skills in chronic psychiatric patients in community residences. Journal of Clinical Psychology, 49(5), 654-662. http:// dx.doi.org/10.1002/1097-4679(199309)49:5 < 654::AID-JCLP2270490 $507>3.0 . \mathrm{CO} ; 2-\mathrm{B}$

Noble, P., \& Rodger, S. (1989). Violence by psychiatric in-patients. The Brit- 
ish Journal of Psychiatry, 155, 384-390.

Pearson, M., Wilmot, E., \& Padi, M. (1986). A study of violent behaviour among in-patients in a psychiatric hospital. The British Journal of Psychiatry, 149, 232-235. http://dx.doi.org/10.1192/bjp.149.2.232

Poulsen, H. D., \& Engberg, M. (2001). Validation of psychiatric patients' statements on coercive measures. Acta Psychiatrica Scandinavica, 103 (1), 60-65. http://dx.doi.org/10.1111/j.1600-0447.2001.00146.x

Steinert, T., Wiebe, C., \& Gebhardt, R. P. (1999). Aggressive behavior against self and others among first-admission patients with schizophrenia.
Psychiatric Services, 50(1), 85-90.

Tedeschi, J. T., \& Felson, R. B. (1994). Violence, aggression, and coercive actions. Washington, DC: American Psychological Association.

Walker, Z., \& Seifert, R. (1994). Violent incidents in a psychiatric intensive care unit. The British Journal of Psychiatry, 164, 826-828. http://dx.doi. org/10.1192/bjp.164.6.826

Yudofsky, S. C., Silver, J. M., Jackson, W., Endicott, J., \& Williams, D. (1986). The overt aggression scale for the objective rating of verbal and physical aggression. American Journal of Psychiatry, 143(1), 35-39. 